\title{
Influence of social media marketing on the performance of hotel industry: a study in Chandigarh Tri-city
}

\author{
Reena Lakha, Research Scholar, University School of Management Studies, Rayat Bahra \\ University, Mohali, Punjab, India. reenarbu@gmail.com \\ Prof (DR) A C Vaid, University School of Management Studies, Rayat Bahra University, Mohali, \\ Punjab, India. registrar@ rayatbahrauniversity.edu.in
}

\begin{abstract}
This research paper illustrates the need of social media marketing in expanding the hotel businesses of the Chandigarh tri-city. Internet services being present in the tri-city allow the effective implementation of digital marketing strategy. This research paper highlights the available of swift transportation facilities, tourist sites, and technological parks as the primary factors leading to the emergence of hotel businesses in the tri-city. The research paper involves conduction of online survey to evaluate the indulgence on varied age group in social media platforms like Facebook and Snap chat. Also, implication of CSR marketing strategies and collaboration between IT and marketing departments in an organization to improve the social media based business promotions have been illustrated in this study. On the other hand, the paper also discusses the CSR driven marketing strategies aid to provide a competitive advantage to hotel businesses by ensuring recognition from social influencers due to the community welfare oriented business methods. Thus, organizations in the hospitality sector who are able to promote their community service driven programs on social media platforms receive stakeholder recognition.
\end{abstract}

Keyword-CSR strategies, hotel industry, social media, social media marketing, social media platforms, tourist sites

\section{INTRODUCTION}

\section{Aim of research}

Digital marketing strategies are crucial for ensuring a competitive advantage to business ventures. This research paper aims to illustrate the significance of social media marketing in improving the business operations of the hotel industry operating in the Chandigarh tri-city. The tricity comprises of Chandigarh, Panchkula and Mohali that are interconnected with each other through internet services. Implementation of social media oriented business promotion schemes and its effectiveness in receiving stakeholder recognition and optimum profitable standards is discussed in this research paper.

\section{Research objective}

- To implement social media marketing strategies in promotion of hotel businesses

- To incorporate CSR strategies in marketing policies

- To improve the technological infrastructure of hotel businesses

- To implement a proper budge plan for hotel businesses

- To ensure optimum cyber security standards

Research question

$\checkmark$ What is the significance of social media marketing in hotel businesses?

$\checkmark$ Why are CSR-driven marketing policies important for stakeholder engagement? $\checkmark$ Why is it crucial to improve the functioning of the IT units in varied businesses of the hospitality sector?

$\checkmark \quad$ What is the significance of maintaining a proper financial budget in the company?

$\checkmark \quad$ What is it essential to have high cyber security in online business operations?

\section{Research background}

The increased commercial development in this portion of northern India has allowed the hospitality sectors to establish themselves in the tri-city. Accessibility to transportation, healthcare services and tourist destinations has made the tri-city a hub or tourism and hotel businesses. The union territory (UT), Chandigarh has a compact and efficient administration system due to its direct supervision under the central government [11] [28]. The international airport thriving in the UT connects in to major domestic and international destinations. Moreover, an effective railways network allows the city to be connected to the major metropolitan cities of India like Mumbai, Chennai, and Delhi. Moreover, the tri-city serves as a hub for oversee operations in the states of Himachal, Jammu \& Kashmir and Punjab. Thus, the tri-city being a hub for major commercial and tourism sectors has proved to be a major opportunity to hospitality businesses. Chandigarh constitutes four major luxury hotels namely the Taj Chandigarh, Mountview, JW Marriot, and Parkview. In addition, the UT comprises of many smaller hotel chains with customer service facilities like the Maya Palace. The industrial parks namely Techno Park and other commercial centers that are present in the tri-city make it a major 
attraction for corporate clients and business travellers. Hence, the major commercial hotels cater to travellers on business tours. The major sectors that draw corporate clients in hotel businesses include IT, telecommunications, Real estate, and legal sectors [6]. In addition, a significant increase in the business travellers from the Pharma sectors has been observed over the recent years. Chandigarh being recognized as a major IT city with significant development in the medical infrastructure has been able to attract more corporate clients in its hotels and tourism centers. International airport development in Mohali and it being a host of major sport events like the IPL has allowed the hospitality businesses to flourish and ensure sustainable business operations [1].

Certain social media marketing agencies that have established themselves in the tri-city allow hotel business to implement social platform oriented business promotion schemes. The major luxury hotel 'Hyatt Regency' that has established itself in Chandigarh adopts effective social marketing strategies to attract international clients [16] [28]. The social platform oriented business promotion has allowed the emerging hospitality market of the tri-city to receive recognition from foreign clients and investors. This premium hotel has managed to receive stakeholder recognition through CSR driven business promotions over social media platforms [10]. Thus, the increased recognition and establishment of a strong brand image has allowed the business to expand its target market. 'Sunshine 42 ' is another major hotel that operates in the tri-city and has managed to attract foreign clients through business promotions in Instagram and Facebook. The company has an official Facebook page that allows potential clients to be informed of the new policies and discount schemes on hotel reservation. Clients satisfied with the service often leave useful review comments that might help potential clients to evaluate the expected standards of service [17].

However, certain hotel chains operating in the tri-city have their own collaborative marketing and IT team that manage their social marketing operations [2]. Independent social marketing team of hotels prevents the risk of legal conflict and security breach as might be associated with external agencies. Digital comparison tools and other feedback facilities over business promotion schemes allow executive leaders of business to perceive the demand of distinct client groups. Hence, client oriented business policies ensure sustainability of business operations and secures the future goals of the hotel companies.

CSR driven business promotions on social platforms allow businesses to receive recognition from major social influencers and thus attract masses. Corporate Social Responsibility helps organizations to attract major stakeholders and establish a sharp brand image. Taj Chandigarh has implemented CSR driven social media promotions to receive recognition from varied clients. Voluntary participation of clients in promoting the social commitments of the organization has helped building a sharp brand image. Thus, the hotel business has managed to achieve a competitive advantage over other luxury hotel chains [12].

Major digital marketing partners provide promotion features like Box footer advertisements, feature advertisements and sponsorship advertisements that allow varied hotel brands to promote their vision and mission statement in online portals and other social networking sites [8]. However, major hotel brands need to enter into effective partnerships with social media platforms like Facebook and Snapchat to receive mass recognition and achieve a competitive advantage. Digital comparison tools allow clients to compare the services offered by a hotel company and select the preferred service. Such stream communication and feedback driven promotions aid hotel businesses to implement customer centric business policies and ensure business sustainability. Innovative methods of social media promotions that feature the unique services and loyalty discounts that a hotel might offer to its loyal clients provide a competitive advantage during high demand periods. Thus, social media based marketing schemes might increase business demands and help to improve the national economy through the consistent growth of hotel businesses in the tri-city. Also, effective collaboration between the technical and marketing department of a hotel company might help to control the online business operations with greater ease and higher standards of security [7]. Thus, social media platforms like facebook, Snapchat, Youtube and Pinterest might influence business promotions on online portals through varied feedback response from clients distributed globally. Businesses which are able to make successful online promotions might have a competitive advantage in this digitalized era. Thus, hotels that are able to adopt innovative methods of business promotions by utilizing online portals might be able to receive mass recognition. Increased stakeholder recognition helps to improve the service rate and thus lead to increased generation of revenue by promoting excellent accommodation facilities to travellers and tourists.

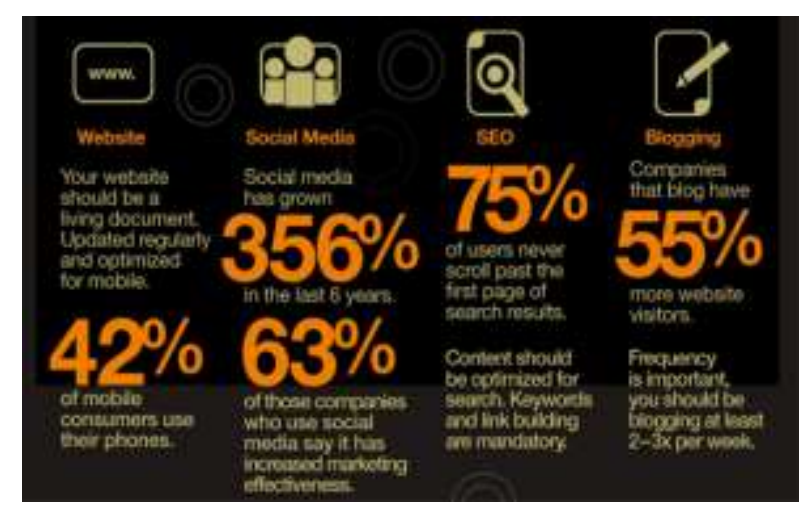

Figure 1: Usage of Social media in hospitality industry

(Source: Aswani, and Gugloth, 2017) [1] 


\section{LITERATURE REVIEW}

[18] Vinerean Simona, (2017), the researcher conducted a survey of varied age groups to evaluate the significance of Social media platforms like Facebook, YouTube and Snapchatas major online communication portals that allow varied clients and consumers to connect to business ventures located in varied regions. Moreover, the researcher has also highlighted the social networking sites help potential stakeholders to recognize services and products offered by businesses through their brand promotions in social media platforms. Modern lifestyle standards and global digitalization has made the social networking sites a major communication hub for global citizens. Hence, to ensure effective promotion of the vision and mission statement of business operations, corporate firms need to need to adopt social media marketing policies. Such strategies provide a competitive advantage and aid to achieve business expansion. However, businesses that fail to implement a proper IT infrastructure may not be able to secure its business related online data from cybercrime. Thus, collaboration between marketing and the IT department is crucial for business promotions through social networking sites.

[19] Bhatnagar, and Dheeraj, (2019) [2] the researcher has illustrated the significance of diligent housekeeping service of major hotels in the Chandigarh Tri-city to lead in the development of concerned hotel businesses as an emerging market for foreign investors and clients. The researcher has conducted a questionnaire method to evaluate the business policy's competence in receiving client satisfaction. The questionnaire has been conducted to receive feedback from clients about the services received from housekeeping staff of major hotels in the tricity. Thus, the research study led to infer that diligent client service might help to build a sharp brand image.

[20] Aswani, and Gugloth, (2017) the researcher has conducted a secondary data collection method through magazines and newspapers to evaluate the importance of digital marketing in hotel businesses. Moreover, the researcher illustrates the significance of blending marketing with CSR oriented business goals. Streamlined communication with customers by implementation of digital communication tools through the portals of Facebook and other social media platforms might aid to perceive the requirements of distinct clients. Hence, a successful promotion campaign through social media portals might help to implement a client oriented vision and mission statement. Moreover, effective communication and business strategy allow businesses to continue expansion and survival. The author has also discussed the social media platforms are an effective way of ensuring promotions on a large scale that might draw recognition from clients across the world. However, social networking based marketing strategy requires businesses to have an effective budget scheme to be able to invest in the marketing activities. Moreover, a strong IT backup is essential to track on the online business operations and ensure that the all business related operations are protected from online breaches. Implementation of online collaboration tools help the IT and marketing departments to coordinate their activities and ensure optimum functioning of online business activities. Such business promotions over online portals ensure recognition from major investors who might be attracted to the CSR oriented business promotions on online social platforms. Thus, the research study led to infer that collaboration between marketing and IT units is need to be implement effective business promotions through online portals.

[21] Aswani, and Gugloth, (2017) [1] the researcher conducted study through secondary data collection and inferred that hotels operating in the tri-city need to implement effective social media based promotion strategies to receive a competitive advantage and allow expansion of business. Social media platforms allow might help emerging markets to receive acknowledgement from international investors and thus secure future goals of business. Streamlined communication between potential clients and executive leaders of businesses might help receive client feedback on the effectiveness of business activities to fulfill their dynamic demands. Hence, determination of business goals followed by evaluating the target audience might help to implement useful social media based promotions of business. However an efficient budget planning is crucial to prevent financial pressures on the company to execute its marketing plan on social media platforms. Thus, the research study states that effective marketing strategy might help to improve the business performance.

[22] Siddiqui.A, Kakkar.k.k, et al., (2019) the researcher conducted a survey to determine the technological advancement in the tri-city. The author has also discussed about the establishment of both luxury driven and financially affordable hotel chains have helped to achieve market expansion and business growth. Thus, the growth of hotel businesses has allowed in improving the business standards of the country. Moreover, consistent improvement in the transportation sector with the construction of new road networks and businesses have allowed businesses to flourish and develop in the tri-city. Hence, major national and international investors have recognized the commercial potential of the emerging markets in the tri-city especially the hospitality sector. Such competitive advantage and scope for business expansion has allowed other major business ventures to open their hotel chains in the tri-city attracting more domestic and international tourists. The Oberois and ITC have established major hotel chains in the tri-city and have contributed in expanding the sustainability of hotel and tourism businesses. However, Panchkula, is yet to receive 
recognition from major stakeholders due to lack of proper recognition from major hotel brands and cost-effective transportation facilities. Tricity events portal is a major digital marketing services thriving in the Union territory to allow business ventures operating near Mohali, Panchkula and Chandigarh to ensure swift online business operations. This highly advanced networking system allows $\mathrm{s}$ the potential clients to have streamlined communication with the hotel owners and tourism guides. Moreover, online portals help hotel businesses to connect with vendors offering taxi services and other transportation personnel. Thus, the infrastructural development and availability of swift transportation facilities enabled the growth of hotel business in the tri-city.

[23] According to Hanlon. Annmarie, David. Zbinden, (2019) the researcher highlights the significance of the Forrester's 5Is business model in improving stakeholder engagement in business operations. The major elements of this business include Involvement, intimacy, interaction and influence that a business stakeholder has with the company over consistent times. The model depicts major elements that might influence the business performance. Firstly, involvement is the aspect which depicts the ability of digital promotions to influence stakeholder engagement in execution of business operations. The effectiveness of online promotions over social media platforms is governed by the ability of such promotional methods to draw recognition from masses, which involve clients from distant places worldwide. Secondly, interaction is the feature that denotes the client feedback schemes that all effective online promotions are made equipped with Digital comparison tools allow potential consumers to communicate their demands and probable expectations from the concerned commercial firms in terms of services offered. Feedback schemes help to implement a client oriented vision statement of business. Also, online communication tools help potential investors to interact with executive leaders of the company and have an idea of the business policies and organizational culture that drives the operations of the concerned corporate firm. Thirdly, intimacy is the feature that denotes the level of stringency that online security services associated with the marketing scheme exert on maintains the privacy of clients who respond to online business promotions. This feature allows major stakeholders to give an honest feedback on the business policies and promotion methods that might help the corporate leaders to evaluate their strategies and effectiveness of work methods. Fourthly, influence, is the element of the business model denotes the overall impact that the digitalized promotion scheme has on potential individuals who might influence business profitability. Increased competition has made major business ventures to implement innovative business models to ensure smooth digital promotions of the vision and mission statement of the company. Effective business models on digital promotions aid to provide useful frameworks required for digital auditing, planning, and implementation of innovative business strategies. Thus, this model might be effective in influencing the business growth and productivity.

[24] Kubicka, A, (2016) the researcher of this article has highlighted the Lauterbor's 4Cs model for the hotels which are doing their business operations through online marketing. In addition, the researcher has also considered the model is a modification of the 4P's of marketing mix and is focused on the consumer interests that might be useful for an internal audit and effective compare with the business policies of potent competitors. On the other hand, the researcher has mainly used the secondary research process in order to collect the data. Moreover; the researcher has also discussed the $4 \mathrm{Cs}$ models which are as follows:

Consumer needs and demands- this element denotes the client's perspective that might influence the product execution to suit their demands and optimal standards of expectations.

Cost to content- this element denotes the cost effectiveness of the services and products delivered to consumers.

Convenience to purchase- this element denotes place element of the marketing mix and denotes the product accessibility and delivery system implemented by concerned business venture.

Communication- this element denotes the promotional methods that a adopted by a corporate firm to receive recognition from stakeholders without compromising the economic principles of business.

[25] Ting Hiram, et al., (2019) through an empirical research on Ten Trends Shaping the Future of Marketing: Considerations for the Academics. The researcher has discussed the ten C's of marketing through which the hotels can transform their business model into digital process. Moreover, the secondary research process has been used in order to identify the ten C's of marketing through which the business firms can get benefits from this theory. This model considers each element of the framework of online marketing with 'customer' being the central element and all the other elements are meant to ensure the client satisfaction. This is followed by corporate culture; this element denotes the organizational culture and work policies that might influence the consumer centric goals of concerned company. An ideal organizational culture needs to ensure ethical working methods aid to ensure business profitability without compromising the quality and quantity of services and products delivered to consumers. 
Convenience is the next element which denotes the accessibility of services to clients. Swift delivery services and easy return policies ensure client satisfaction and secure the sustainability goals of business. Communication is the following element which denotes the implementation of inbound marketing and social media based business promotions that might help to receive optimal recognition from clients and ensure smooth flow of business. Next comes Competition, the element denotes the scope given to business competitors to compare each other's policies and growth statistics influenced by their adopted marketing policies. This is then followed by Consistency, the element which denotes the constant pace of optimal service output irrespective of the medium of product transaction. This element ensures the business flexibility to provide efficient services to clients through both online and in-store deliveries. Creative content- this element denotes the necessary efforts needed by corporate firms to consistently upgrade their web based content to ensure clients are aware of their new business policies and product launches. Customization-this element denotes the personalization of official websites and web content that denote the uniqueness of a company and makes to appealing to consumers amidst other potential business competitors. Coordination- this element denotes the integration of various interlinked business operations starting from product execution to its delivery to consumers within allotted time frame and with optimal standards of quality and quantity. Control- this element depicts the utilization of tools for web analysis which help to evaluate the effectiveness of a company's marketing scheme in attracting consumers. Customer feedback tools are a crucial analytical tool that helps measure the effectiveness of varied online marketing campaigns.

[26] Momany and Alshboul (2016), in his article on social media marketing: utilizing social media to advance brand awareness and increase online sales has focused primarily on the utilization of social media for advancing the brand awareness and increasing the online sales. The researcher has also highlighted the importance of social media marketing for hotels to create brand awareness among the customers. As per the author of this article, the emergence of social media has created opportunities for the hotel industry to improve their business performance by retaining the customers. On the other hand, the survey method has been used by the researcher in order to gather data. The application SurveyMoney has been used for distributing the survey among the selected population so that the effectiveness of the study can be understood. It has been observed that the target sample size for this study is 120 and the actual sample size is 144. Moreover, the researchers have also used the Convenience sampling method for selecting the sample for the study.

[27] TomDieck, Jung, Kim and Moon (2017), the researcher has highlighted the usage of social media in luxury hotels. According to the researcher, the Social media platforms have emerged as a leading marketing method to promote business in a wide scale and ensure expansion of market. Moreover, the researcher has conducted 16 interviews and 258 questionnaires with the agents of luxury hotels. On the other hand, thematic analyses along with partial least square analysis have also been used by the researcher in order to collect the data. The researcher has also discussed about the renowned social media platforms like Facebook and Snapchat have developed as prime source of communication that allows people from varied regions of the world to stay connected. With the blooming growth of hotel businesses, this emerging market needs to adopt social media marketing strategies to attract both domestic and international clients and investors. Hotels and other hospitability units need to adopt necessary changes to implement effective social marketing strategies to gain a competitive advantage.

[28] Ahlawat.R (2018), in a study on Environment Friendly Practices Followed by Chandigarh Hotels: A Study of Luxury Chain Hotels' Websites focused on the innovative digital marketing strategy in the tri-city to gain competitive advantage. The researcher has conducted a study to describe the significance and emergence of ecohotels in the Chandigarh Tri-city. The study highlights the eco-friendly practices implemented by major premium and luxury hotels operating in Chandigarh, Panchkula and Mohali. The use of natural and eco-friendly products in the house keeping units, effective management of waste generated and utilizing of renewable sources of energy are some eco-friendly practices.

Implementation of such practices has allowed concerned hotel businesses to acknowledge the Corporate Social Responsibility (CSR) driven business policies. CSR oriented vision and mission statement of the businesses have been observed to help in building a sharp brand image and allow maximum recognition from stakeholders. The researcher has conducted the study by utilizing secondary data and resources from websites of concerned hotels, magazines, and journals. The Taj hotel has initiated a program named EARTH (Environmental Awareness and Renewal at Taj Hotels) that involves the use of natural and reusable products in hotel along with energy efficient equipment of daily errands of the hotel. Furthermore, the initiative involves periodic 'Community welfare participation' programs in which the hotel workforce volunteers in conducting community services that include charitable donations, volunteering for cleaning roads and parks in the community. JW Marriott has been reported to have sustainable policy on food and beverage utilization along with sustainable policies in context to sea food position. These allow clients to be provided with high quality unadulterated food products that might ensure client satisfaction. The Oberoi group of hotel primarily operates by utilizing natural and recyclable products as far 
as possible. In the year 2014, the Hyatt regency put forward its vision statement intended to be completely implemented by 2020. The vision statement involved reduction of water usage, implementing energy efficient working methods, and reducing waste generation. The park plaza has implemented business practices like carbon reduction, which aims to use alternative sources of energy by harnessing solar and wind energy. Executive leaders often arrange meetings with major stakeholders to discuss the Green environment oriented vision and mission statement of the hotel company. The company also focuses to implement effective water conservation procedures and ensure proper disposal and management of waste. Such practices have helped the hotel company to receive recognition from both domestic and international clients. Moreover, eco-friendly methods of work ensure safety and security to workers and allow retention of diligent staff members which in turn secures the future goals of business.

The Park plaza has an official website that illustrates the social responsibility oriented business policy and work methods under the vision and mission statement 'Think Planet'. Such digital marketing methods have allowed clients and investors to acknowledge the community welfare initiative s taken by the business and help to build a sharp brand image. Thus, the CSR policies of mentioned hotel companies have ensured competitive advantage and led international clients to recognize the commercial potentials of the emerging hotel business in the tri-city. Moreover, the environmental friendly business operations have lead to improve the community welfare standards and ensure all round sustainable development.

\section{RESEARCH METHODOLOGY}

In this research study Stratified random sampling method has been used to conduct a survey for evaluating the influence of social media platform in improving business promotions and receiving stakeholder recognition. In this paper, the researcher has conducted the survey method for collecting the data. For doing this, the researcher had set an open-ended question which was asked to the managers of the hotel in order to analyze the impact of using social media. However, the increased lifestyle changes and digitalization is influencing senior adults to actively use social media platforms to remain updated with modern lifestyle requirements. Thus, the identification of the target audience is pivotal requirement of social media oriented promotion of hotel business. It has been evident that Social media promotions prove to be effective when the company adopts an innovative method to portray its vision and mission statement. Unique promotions and advertisements that put provide the unique features of the hotel services helps to overshadow the service commitments of competitors. Moreover, advertisements that highlight the transportation partners of the company along with tourist guides and other customer centric privileges helps to maximize client engagement over the web content. Consistency in business promotions over social platforms allow hotel companies to ensure retention of loyal clients by consistently introducing new service packages and loyalty programs. In addition, collaboration with reputed travel agencies might help to provide clients with secure travel experience in and out of the hotels.

\section{CONCLUSION}

Considering the various ways social media affects individuals and businesses alike, as a result, social media marketing might help to receive maximum recognition from both foreign and domestic clients and ensure smooth flow of business operations. The implementation of this technologically innovative promotion method might help business ventures to receive competitive advantage. However, collaboration with external agencies for social media oriented promotions might add financial pressure and might have the risk of legal disputes. Thus, collaborative operation between the IT and marketing department within the concerned hotel company might help to ensure effective and consistent implementation of marketing on social media platforms. Chandigarh tri-city with technological advancement and access to major international airports has developed into a hub of hospitality businesses. Effective implementation of social media marketing might help this emerging market of hospitality businesses to receive recognition from foreign clients and investors. Furthermore, the presence of large medicinal institutions, technological parks and Pharmaceutical industries attract business clients to hotels of the tri-city. Presence of both premium and cost effective hotels with high quality customer services has allow the tri-city to receive recognition from tourists belonging to varied economic backgrounds. Also, the effective implementation of CSR strategies of business promotions aids to increase the effectiveness of the social media oriented promotions. Effective implementation of CSR driven business strategies aid to build a sharp brand image and ensure business sustainability. Recognition from foreign clients might allow these emerging markets of hospitality sectors to improve the economic standards of the nation. Hence, recognition from social influencers aid to build a strong brand image and receive recognition from the masses. Moreover, the online survey led to highlight the target age group, which is influenced by social media oriented promotions. Thus, younger generation being familiar with technology and browsing are the most active users of social networking sites.

\section{RECOMMENDATION}

\section{Collaboration between IT and marketing departments}

Hotel businesses need to ensure effective collaboration between their technical and marketing staff to secure 
promotions of business operations on online portals. On the contrary, partnership with external agencies of social marketing might increase the risk of security breach and probable legal disputes with concerned agencies. Moreover, internal social marketing management team might aid to reduce the financial pressure of implementing effective social media oriented business promotion strategies. Hence, hotel companies with workforce possessing effective communication and analytical skill might help to perceive the client demands in context to accommodation services that the hotel may offer.

Moreover, innovation driven vision statement allows IT personnel to implement new promotion schemes that might provide the online viewers consistent information regarding new services offered by concerned hotels and an affordable price rates. Hence, attractive discounts on services during festivals and other periods of high demand of hotel accommodations might provide competitive advantage to concerned hotels.

\section{Effective analysis of target market}

Social media is a popular communication tool among younger generations and hence social media based marketing strategies might majorly influence younger consumers. However, hotel businesses cater to the needs of varied clients irrespective of their age. Hence a preliminary analysis of target consumers and their acquaintance with social networking is crucial to ensure effective business promotions on online portals. Diligent data analyst might aid to accurately evaluate the target audience's acquaintance with social networking. Preliminary evaluate of target market is crucial to conserve the economic principles of business while investing in online marketing campaigns. This evaluation is crucial for ensuring smooth flow of business operations and makes optimal profits through increased service demands from clients.

\section{REFERENCE}

[1] Aswani, V. and Gugloth, S.(2017), "Social Media Usage as Communication Tool by Hospitality Industry", In National Conference on Marketing and Sustainable Development October (Vol. 13, p. 14).

[2] Bhatnagar, E. and Dheeraj, N. (2019), "Impact of Housekeeping Services and Practices on Customer Satisfaction and Repeat Business", Prabandhan: Indian Journal of Management, 12(8), pp.46-57.

[3] Bhatnagar, E. and Dheeraj, N. (2019), "Impact of Housekeeping Services and Practices on Customer Satisfaction and Repeat Business", Prabandhan: Indian Journal of Management, 12(8), pp.46-57.

[4] Castro, J., Gómez, D., Molina, E. and Tejada, J. (2017), "Improving polynomial estimation of the Shapley value by stratified random sampling with optimum allocation", Computers \& Operations Research, 82, pp.180-188.

[5] Cekim, H.O. and Kadilar, C. (2019), "In-type estimators for the population variance in stratified random sampling", Communications in Statistics-Simulation and Computation, pp.1-13.

[6] Gaur, S., Sharma, L. and Pandya, D.D. (2019), “A perception of ICT for social media marketing in India", In Computing and Network Sustainability, (pp. 485-495). Springer, Singapore.

[7] Jung, T.H., Dieck, M.C.T. and Chung, N. (2018), "Determinants of hotel social media continued usage", International Journal of Contemporary Hospitality Management.

[8] Parvez, S.J., Moyeenudin, H.M., Arun, S., Anandan, R. and Janahan, S.K. (2018), "Digital marketing in hotel industry", International Journal of Engineering \& Technology, 7(2.21), pp.288-290.

[9] Paweł Cegliński, Anna Wiśniewska ( 2017), “CSR as a Source of Competitive Advantage: The Case Study of Polpharma Group", Journal of Corporate Responsibility and Leadership Vol. 3(Issue 4):57-70. DOI: 10.12775/JCRL.2016.020

[10] Kaur, Inderjot (2019), "CSR in hotel industry in India. In Corporate Social Responsibility: Concepts, Methodologies, Tools, and Applications (pp. 936-954). IGI Global.

[11] Kaur, Savneet (2016), "CSR in Indian Tourism and Hospitality Industry: A Special Reference to Aviation and Hotel Industry and CSR Initiatives by Punjab, Haryana, and Himachal Tourism", In Corporate Social Responsibility in the Hospitality and Tourism Industry (pp. 106-117). IGI Global.

[12] Kaushik, P.C. and Khanna, K. (2017), "Is social hotel the future of Indian hospitality?", International research journal of management, IT and social sciences, 4(1), pp.71-77.

[13]

http://chandigarhenvis.gov.in/beta/EnvisPdfFiles/cdp.pdf

[14] Malik, H. and Sharma, M. (2019), “E-Marketing as a Tool to Achieve Competitiveness in Travel Trade Industry", In Handbook of Research on International Travel Agency and Tour Operation Management (pp. 272283).IGI Global.

[15] N. Rana \& U. Majmuda (2016), "Building reputation through social media: The CSR context”.

[16] Naresh, M.N.R. (2019), "Impact of customer cocreation through social media in India”.

[17] Parvez, S.J., Moyeenudin, H.M., Arun, S., Anandan, R. and Janahan, S.K. (2018), "Digital marketing in hotel 
industry", International Journal of Engineering \& Technology, 7(2.21), pp.288-290.

[18] Simona Vinerean (2017), "Importance of Strategic Social Media Marketing", Expert Journal of Marketing 5(1), pp. 28-35

[19] Bhatnagar, E. and Dheeraj, N. (2019), "Impact of Housekeeping Services and Practices on Customer Satisfaction and Repeat Business", Prabandhan: Indian Journal of Management, 12(8), pp.46-57.

[20] Aswani. V and Gugloth.S(2017), "The role and importance of social media for hotel industry". http://www.aims-

international.org/myconference/cd/PDF/MSD2-4912-

Done.pdf

[21] Aswani. V and Gugloth. Sardar (2017), "Social Media Usage as Communication Tool by Hospitality Industry", National Conference on Marketing and Sustainable Development October (Vol. 13, p. 14).

[22] Asfa Siddiqui, K. K. Kakkar, Suvankar Halder, Pramod Kumar," Smart Chandigarh Tri-City Region: Spatial Strategies of Transformation" In book: Smart Metropolitan Regional Development: Economic and Spatial Design Strategies, Chapter: 7, Publisher: Springer, DOI: $\underline{10.1007 / 978-981-10-8588-8 \quad 7}$
[23] Hanlon. Annmarie, David. Zbinden (2019), "The Forrester's 5Is business model", Digital Marketing Models Frameworks and tools for digital audits, planning and strategy.

[24] Kubicka, Anna (2016), "Personalized information management by online stores in 4C model.Case study. Foundations of Management", 8(1), 53-68. DOI: https://doi.org/10.1515/fman-2016-0005

[25] Ting, H., Fam, K.S., Chan, Y.W. and Cheah, J.H. (2019), "Editorial-Ten Trends Shaping the Future of Marketing: Considerations for the Academics", Asian Journal of Business Research Volume, 9(1). https://www.magscholar.com/ajbr/ajbrv9n1/ajbr190052.pd $\underline{\mathrm{f}}$

[26] Momany, M. and Alshboul, A. (2016), "social media marketing: utilizing social media to advance brand awareness and increase online sales", International Journal of Business, Marketing, \& Decision Science, Vol. 9 Issue 1, p33-54. 22p.

[27] tomDieck, M.C., Jung, T.H., Kim, W.G. and Moon, Y.(2017), "Hotel guests' social media acceptance in luxury hotels", International Journal of Contemporary Hospitality Management29(1):530-550. DOI: 10.1108/IJCHM-10$\underline{2015-0552}$

[28] Ahlawat, R. (2018), "Environment Friendly Practices Followed By Chandigarh Hotels: A Study of Luxury Chain Hotels'websites". 